\title{
ANALISIS FAKTOR - FAKTOR YANG MEMPENGARUHI ADOPSI TWITTER ADVERTISING PADA SEGMEN MUDA USIA 15 - 24 TAHUN WILAYAH JABODETABEK (JAKARTA, BOGOR, DEPOK,TANGGERANG, BEKASI) TAHUN 2011
}

\author{
Edith Lavindri \\ Program Studi S2 MM Eksekutif Muda \\ Sekolah Tinggi Manajemen PPM \\ Pepey Riawati Kurnia \\ Sekolah Tinggi Manajemen PPM
}

\begin{abstract}
Teori dan Model Theory of Reasoned Action (TRA) dari Fishbein \& Ajzen (1975), Theory Planned Behavior (TPB) dari Ajzen (1991), Technology Acceptance Model (TAM) dari Davis (1989) dan Diffusion of Innovation Model (DOI) dari Rogers (1983 dalam Rogers, 2003) sering digunakan oleh banyak peneliti untuk menemukan faktor - faktor yang mempengaruhi adopsi yang berkaitan dengan teknologi. Pada penelitian ini keempat teori dan model ini dikombinasikan guna menjelaskan faktor - faktor yang mempengaruhi adopsi Twitter advertising pada segmen muda usia 15 - 24 tahun. Sebanyak 389 penguna Twitter menjadi responden penelitian ini, dimana 5 diantaranya diwawancara untuk mendapatkan pemahaman mendalam akan adopsi Twitter advertising. Hasil analisis menunjukkan bahwa terdapat attitude terhadap Twitter advertising, subjective norm terhadap Twitter advertising, perceived usefulness terhadap Twitter advertising berpengaruh dan signifikan terhadap intention to adopt Twitter advertising.
\end{abstract}

Keywords:

Adopsi, Twitter advertising, segmen muda, Theory of Reasoned Action (TRA), Theory Planned Behavior (TPB),Technology Acceptance Model (TAM) dan Diffusion of Innovation Model (DOI) 


\section{PENDAHULUAN}

Masyarakat Indonesia telah bergeser menuju masyarakat cyber dengan jumlah yang sangat besar. Pengguna internet di Indonesia berjumlah 30 juta, 20,8 persen diantaranya merupakan pengguna Twitter (Suwarna\&Febriane, 2010) yaitu aplikasi sosial media gratis yang memungkinkan penggunanya untuk mengirimkan status terkini (update status) kepada kontak mereka atau disebut follower (Glaser, 2007). Bahkan Jakarta menempati kota ke 13 diatas Tokyo dimana populasi pengguna Twitter berada.

Dampak dari hadirnya media ini membuat para marketer memanfaatkan Twitter semaksimal mungkin sebagai media promosi baru yang inovatif dan efektif dalam berkompetisi mendapatkan perhatian dari target konsumen. Sistem pada Twitter dapat membantu perusahaan untuk berinteraksi dengan konsumen dan menciptakan buzz karena sifat percakapan dipublikasikan berupa update status. Tulisan pada update status tersebut dapat dilihat oleh follower dan reaksi yang dapat ditimbulkan dari update status tersebut adalah apakah mereka mereplay atau meretweet (RT).

Reaksi follower inilah yang dipercaya marketer sebagai sebagai bola es yang bergulir untuk merekomendasikan suatu produk ke teman teman lainnya di Twitter. Sebuah survei 2009 oleh Mzinga dan Babson Executive Education menemukan bahwa $86 \%$ dari profesional pemasaran dalam berbagai bidang menggunakan media sosial dalam upaya pemasaran dan komunikasi mereka (Koutalakis, 2009). Twitterpun dimasukkan sebagai media mix dalam berpromosi online sebagai usaha mengintegrasikan situs web dan jejaring sosial.

Kehadiran Twitter membuka peluang besar untuk melakukan promosi brand kepada dan melalui segmen muda karena nge-tweet (tweeting berarti tindakan posting pada sebuah microblog pada Bilgihan \& Nusair, 2009) saat ini merupakan bagian dari gaya hidup dan kebiasaan anak muda. Peluang besar itu tercipta karena Twitter merupakan media promosi yang penting mengingat segmen muda yang mencari informasi dan mereka gemar bertukar informasi melalui internet (Tapscoot, 2009).

Pendapat Rosner (1996) dalam Fethi Calisir (2003) yang mengatakan bahwa pelajar adalah frequent user dari internet dan mewakili target segmen yang penting untuk memahami promosi melalui internet pada masa sekarang dan yang akan datang memperkuat pentingnya penelitian terhadap segmen muda. Untuk itulah penelitian ini berusaha mendapatkan data mengenai faktor yang mempengaruhi keinginan segmen muda mengadopsi Twitter advertising. Dengan meneliti faktor - faktor yang mempengaruhi adopsi segmen muda, dapat diprediksi perkembangan pemakaian Twitter sebagai media promosi di masa depan karena pengukuran behaviour intention merupakan prediktor dari usage behaviour (Ajzen \& Fishbein, 1980 dalam Khan \& Allil, 2010).

Penelitian ini merupakan usaha untuk mengkaji adopsi Twitter dari sudut pandang individu dalam konteks Twitter advertising. Dengan diadakan penelitian mengenai adopsi Twitter advertising dari sudut pandang individu akan melengkapi pemahaman mengenai adopsi Twitter advertising. Hal ini dikarenakan penelitian mengenai Twitter yang telah dilakukan lebih mengarah ke topik Twitter sebagai media informasi (Bilgihan et al., 2009; Shelton, 2009), mengkaji faktor yang mempengaruhi seseorang untuk terus menge-tweet (Liu,Cheung\&Lee,2010; Zhao\&Lou,2010), adopsi Twitter sebagai media marketing perusahaan (Grainger, 2010; Dunn; 2010), adopsi Twitter sebagai media komunikasi perpustakaan dengan anggotanya (DeVoe, 
2009; Le Gac, 2010) dan adopsi aplikasi Twitter khususnya hastag\# dilihat dari aspek komunikasi dan interaksi manusia (Chang, 2010).

\section{PENDEKATAN PENELITIAN}

Twitter, mobile dan wireless tidak dapat dipisahkan pada penelitian mengenai adopsi Twitter advertising ini karena dalam penggunaanya mereka bersamaan. Twitter merupakan aplikasi mobile, dimana $46 \%$ dari pengguna Twitter yang aktif mengakses Twitter melalui mobile, hal ini dinyatakan oleh CEO Twitter, Evan Williams. Wireless yang terdapat pada mobile dinyatakan oleh Jamalipour, 2003 tidak hanya sebagai menghubungan mobile dengan servis internet dimanapun dan kapanpun tetapi merupakan integrasi dari internet dan teknologi komunikasi di dalam satu sistem yang meliputi seluruh kebutuhan manusia. Sehingga dapat dinyatakan bahwa dengan adanya koneksi internet tersebut maka pengguna mobile dapat mengaksakses Twitter melalui aplikasi mobile dan berkomunikasi melalui Twitter. Oleh sebab itu, peneliti mengkaitkan adopsi Twitter advertising dengan adopsi mobile services, adopsi mobile advertising, adopsi mobile marketing dan adopsi wireless advertising.

Rogers, 1983 (dalam Rogers, 2003) mendefinisikan adopsi sebagai keputusan untuk menggunakan secara penuh dan utuh sebuah inovasi. Pada penelitian ini, adopsi berarti menggunakan secara penuh dan utuh dari Twitter advertising. Penggunaan ini berarti tindakan nyata dari seseorang terhadap Twitter advertising yaitu menjadi bagian dari akun resmi Twitter suatu brand (menjadi follower brand tertentu), membagi informasi yang didapat Twitter advertising kepada peer groupnya (dengan melakukan re-tweet), ikut melakukan kampanye dengan penggunaan \#hastag. Tindakan nyata tersebut adalah parameter seseorang telah mengadopsi Twitter advertising.

Kombinasi teori dan model yang digunakan guna mencari faktor - faktor yang mempengaruhi segmen muda mengadopsi Twitter advertising adalah Theory of Reasoned Action (TRA) dari Fishbein \& Ajzen (1975), Theory Planned Behavior (TPB) dari Ajzen (1991), Technology Acceptance Model (TAM) dari Davis (1989) dan Diffusion of Innovation Model (DOI) dari Rogers (1983 dalam Rogers, 2003). Keempat model tersebut merupakan model yang sering digunakan oleh banyak peneliti untuk menemukan faktor - faktor yang mempengaruhi adopsi yang berkaitan dengan teknologi dengan menjelaskan intention to use the technology dan behavioral intention (Tanakinjal, Deans \& Gray, 2010, Chou \& Chou, 2009; Khan \& Allil, 2010; Chen, 2009; Lee,2008; Sendencka, 2006; Lee, 2003).

Pada teori dan model TRA (Fishbein \& Ajzen, 1975), faktor terpenting dari consumer actual behaviour adalah intention to behave. Terdapat dua faktor yang mempengaruhi adanya intention to behave yaitu attitudes toward the behavior dan subjective norms. Ajzen (1991) merevisi TRA dan mengusulkan variabel perceived behavioural control dalam teorinya, teori tersebut dinamakan sebagai TPB. Pada Lee, (2003), TPB dijadikan teori dasar studi mengenai adopsi mobile technology, oleh Lee, (2008) TPB dipergunakan untuk memprediksi penggunaan online video advertising.

Beberapa penelitian yang membahas adopsi mobile advertising (Khan \& Allil, 2010), adopsi aplikasi mobile (Sadencka, 2006) dan adopsi telepon genggam berteknologi WAP (Teo\&Pok, 2003) wireless advertising menggunakan TAM sebagai kerangka teori. Pada awalnya, TAM dirancang untuk memprediksi penerimaan 
pengguna teknologi informasi dan penggunaannya pada pekerjaan (Davis 1989). Inti dari TAM adalah niat untuk menggunaan suatu sistem (intention to use a system) yang dipengaruhi oleh dua hal yaitu, perceived usefulness dan perceived ease of use.

Pada Teo \& Pok, 2003, DOI digunakan sebagai teori acceptance of technology. Dijelaskan dalam teori tersebut terdapat lima determinan yang mempengaruhi adopsi dari sebuah inovasi yaitu relative adventage, compatibility, complexity, trialability dan observability (Rogers, 1983 dalam Rogers, 2003). Menurut Rogers (2003) kelima atribut tersebut secara empiris terkait satu sama lain, tetapi secara konseptual berbeda.

Penelitian oleh Chou \& Chou, 2009 mengenai Facebook dan Myspace sebagai media promosi, Khan \& Allil, 2010 mengenai adopsi mobile advertising dan Lee, 2008 tentang online video advertising membuktikan bahwa teori dan model penerimaan teknologi (technology acceptance) merupakan pendekatan untuk melihat faktor yang mempengaruhi individu dalam mengadopsi teknologi sebagai media beriklan. Untuk itu hipotesis yang peneliti ajukan adalah :

\section{Attitude}

Attitude adalah indikator yang lazim digunakan untuk mengukur keefektifan dari advertising (Jun\&Lee, 2007). Berdasarkan Fishbein \& Ajzen (1975), attitude terhadap suatu objek diartikan sebagai evaluasi internal individu berdasarkan keyakinan seseorang. Dengan kata lain, kepercayaan (belief) merupakan faktor dasar yang membentuk attitude, yang kemudian mempengaruhi behavioural intention (Davis, 1989).

Twitter advertising merupakan sebuah interaksi langsung antara perusahaan dan konsumen, melalui aplikasi Twitter.
Tingkat penggunaan Twitter advertising diatur sedapat mungkin berdasarkan oleh kebutuhan dan keinginan konsumen agar pesan yang hendak disampaikan diterima oleh konsumen (Grainger, 2010). Walaupun pihak perusahaan berusaha sebaik mungkin agar sikap konsumen terhadap Twitter advertising disukai tetapi pada akhirnya konsumenlah yang membentuk sikap kesukaan atau ketidaksukaan yang berpengaruh terhadap keinginan adopsi. Untuk membuktikan pengaruh attitude terhadap Twitter advertising, maka pada penelitian ini diajukan hipotesis :

\section{H1 : Attitude terhadap Twitter advertising mempengaruhi secara signifikan terhadap intention to adopt Twitter advertising.}

\section{Subjective Norm}

Subjective norm berarti persepsi seseorang pada pendapat orang lain mengenai apa yang seharusnya dilakukan atau tidak dilakukan (Fishbein \& Azjen 1975). Pada model dan teori mengenai individual acceptance seperti pada Theory of Reasoned Action (TRA) dari Fishbein \& Ajzen, 1975; Theory of Planned Behavior (TPB) oleh Ajzen, 1991 dan pengembangan Technology Acceptance Model oleh Venkatesh \& Davis, 2000 yang dikenal dengan TAM2, subjective norm merupakan determinan yang mempengaruhi behavioural intention.

Bagi seorang pengguna Twitter, melakukan tindakan follow akun resmi suatu perusahaan, turut serta menyebarkan informasi dengan opsi retweet (RT) dan mengikuti kampanye dengan membubuhkan hastag\# di Twitter berkaitan erat dengan pandangan follower terhadap dirinya. Hal itu disebabkan karena seluruh informasi di Twitter dapat diakses oleh follower dengan bebas untuk mengetahui siapa saja yang difollow dan memfollow dan apabila 
seseorang melakukan penyebaran melalui RT serta update status dengan menggunakan hastag\# semua terlihat di timeline dan langsung terlihat di akun Twitter followernya. Pentingnya pandangan orang lain menyebabkan seseorang berusaha keras untuk tidak di unfollow oleh followernya dengan memperhatikan apa yang ditulis di Twitter. Untuk alasan - alasan tersebut, seseorang akan mempertimbangkan pandangan orang lain terutama followernya untuk mengadopsi Twitter advertising maka pada penelitian ini diajukan hipotesis :

$\mathrm{H} 2$ : Subjective norm terhadap Twitter advertising mempengaruhi secara signifikan terhadap intention to adopt Twitter advertising.

\section{Perceived usefulness}

Perceived usefulness didefinisikan sebagai tingkat keyakinan seseorang bahwa dengan menggunakan sebuah sistem tertentu dapat membantu meningkatkan kinerjanya (Davis, 1989). Berdasarkan model penerimaan teknologi (technology acceptance) dari Davis, 1989 diadopsinya suatu teknologi dipengaruhi oleh persepsi kegunaan (perceived usefulness). Faktor ini kemudian dijadikan faktor penting yang mempengaruhi penerimaan teknologi (Khan\&Allil, 2010; Sanghyun, 2008; SoroaKoury, 2008; $\quad$ Sendecka,2006; Venkatesh,Morris,Davis\& Davis, 2003).

Pada Twitter advertising, seseorang akan menjadi anggota dari official akun atau meretweet atau melakukan \#hastag suatu iklan tertentu melalui Twitter, apabila dirasakan isi dari informasi yang diberikan berguna bagi mereka dan peer group. Salah satu pengguna Twitter, Ira Ahmad dalam blognya mengatakan dapat mengetahui informasi dengan cepat adalah alasan memfollow akun yang dapat memberikannya informasi dengan cepat, mengetahui berita yang menjadi trend sebelum beredar di media massa dan kemampuan berinteraksi dengan pemilik akun. Untuk membuktikan pengaruh faktor perceived usefulness Twitter advertising terhadap adopsi, maka pada penelitian ini diajukan hipotesis : $\mathrm{H3}$
terhadap $\quad \begin{gathered}\text { Perceived of } \begin{array}{c}\text { usefulness } \\ \text { Twitter }\end{array} \\ \text { advertising }\end{gathered}$ mempengaruhi secara signifikan terhadap intention to adopt Twitter advertising.

\section{Compatibility}

Compatibility diartikan sejauh mana suatu inovasi dianggap konsisten dengan nilai-nilai yang ada, pengalaman masa lalu, dan kebutuhan dari pengadopsi (Rogers, 1983 dalam Rogers, 2003). Dalam teori dan model penerimaan teknologi (technology acceptance) dan adopsi, compatibility merupakan faktor yang penting sebagai faktor langsung yang mempengaruhi keinginan melakukan tindakan (behaviour intention). Terdapat beberapa penelitian yang mengkonfirmasi bahwa compatibility dari sebuah inovasi memiliki pengaruh positif terhadap adopsi dari suatu inovasi advertising melalui mobile (Khan \& Allil, 2010; Tanakinjal et al., 2010).

Kesesuaian terhadap nilai, gaya hidup dan norma membuat pengguna Twitter meningkat drastis. Twitter dijadikan wadah untuk percakapan publik, dimana seseorang dapat mengetahui apa yang dilakukan,dipikirkan dan dirasakan peer groupnya dengan melihat time line. Hal ini sesuai dengan nilai masyarakat Indonesia yang kekeluargaan (Doherty, 2010). Pada Twitter advertising, alasan seseorang memfollow akun resmi Twitter dan lebih jauh mengadopsi Twitter advertising dapat dikaitkan dengan kecocokan dengan metode pencarian informasi di internet baik berupa berita maupun mengenai barang dan jasa yang mereka butuhkan. Untuk membuktikan pengaruh faktor kecocokan Twitter 
advertising terhadap adopsi, maka pada penelitian ini diajukan hipotesis :

H4 : Compatibility pada Twitter advertising mempengaruhi secara signifikan terhadap intention to adopt Twitter advertising.

\section{Perceived of Behavioural Control}

Sifat unik Twitter advertising adalah seseorang dapat mengkontrol iklan yang datang pada dirinya melalui user permission. Dalam Twitter agar iklan atau informasi dapat diterima oleh audience, mereka haruslah terlebih dahulu menjadi anggota akun Twitter (follower dalam istilah Twitter) dengan bergabung (follow dalam istilah Twitter) atau dengan menerima permintaan menjadi teman (follow back dalam istilah Twitter). Proses inilah yang merupakan user permission pada Twitter. User permission terjadi ketika seseorang memberikan persetujuan untuk menerima informasi dari sebuah perusahaan (Godin, 1999).

$$
\text { Pada penelitian sebelumnya }
$$

mengenai adopsi terhadap advertising melalui mobile, dibuktikan bahwa perceived control terhadap mobile advertising merupakan faktor kuat yang mempengaruhi keinginan seseorang menerima mobile advertising di India (Khalil \& Allil, 2010). Pada TPB (Ajzen, 1991), perceived behavioural control diuraikan menjadi kepercayaan akan kontrol (control belief) dan perasaan akan kekuasaan (perceived power). Kepercayaan akan kontrol (control belief) adalah keyakinan tentang sumberdaya dan kesempatan yang dapat berupa pengalaman terdahulu dengan perilaku tersebut atau dapat karena dipengaruhi informasi tangan kedua yang dapat meningkatkan atau menurunkan perasaan kesulitan dalam menampilkan perilaku tertentu. Perasaan akan kekuasaan (perceived power) adalah kekuatan faktor kontrol tertentu untuk memfasilitasi atau menghalangi kinerja perilaku (Ajzen, 1991).

Faktor perceived behavioural control terhadap Twitter advertising terwujud pada kemampuan seseorang memilih iklan apa yang ingin dilihat melalui Twitter, seberapa sering pesan iklan diterima dalam satu waktu melalui Twitter, mengikuti dan menghentikan iklan (dengan pilihan follow atau unfollow akun Twitter). Oleh sebab itu kontrol terhadap Twitter advertising dipertimbangkan menjadi faktor yang mempengaruhi keinginan individu mengadopsi Twitter advertising. Sehingga pada penelitian ini diajukan hipotesis :

H5 : Perceived of behavioural control terhadap Twitter advertising mempengaruhi secara signifikan terhadap intention to adopt Twitter advertising.

\section{Awareness of Mass Media Advertising} Advertising awareness didefinisikan oleh Okazaki, 2007 sebagai tingkat kesadaran konsumen dalam melihat pesan dalam iklan pada beberapa media seperti televisi, radio, majalah atau internet. Berdasarkan penelitian Okazaki, 2007 mengenai keinginan untuk mengakses wireless banner advertising membuktikan bahwa semakin sering seseorang berinteraksi dengan pesan iklan melalui mass media semakin positif keinginan untuk mengakses wireless advertising. Pada Khan\&Allil, 2010 dibuktikan kembali bahwa awareness of mass media advertising mempengaruhi secara langsung dan signifikan adopsi advertising melalui mobile di India.

Pada Twitter, upaya melakukan promosi tidak dapat disamakan dengan advertising di media lain karena perusahaan tidak dapat melakukan hard sale seperti layaknya iklan baris (Yoris Sebastian, wawancara oleh Hidayat, 2011 maret $31-13$ April). Konsumen harus menemukan sendiri 
promosi tersebut yang seringkali perusahaan sisipkan pada iklan dan website mereka contoh Tropicana Slim menghubungkan tautan Twitter di website dengan tautan official account Twitter dan mencantumkan hastag \#remember di bagian atas di website mereka. Apabila di mass media pesan promosi dapat terlihat jelas, pada Twitter pesan promosi disampaikan melalui avatar (profile picture Twitter), \#hastag dan memasukkan cerita penggunaan produk atau jasa ke dalam update status. Sifat terselubung inilah yang membuat awareness akan advertising mass media berbeda dengan awareness akan Twitter advertising. Hal ini dikarenakan awareness akan advertising mass media berkaitan akan kesadaran bentuk pesan sedangkan pada awareness akan Twitter advertising dikaitkan dengan kesadaran seseorang akan suatu perusahaan memiliki akun resmi Twitter, berpromosi melalui akun resmi tersebut dan melakukan kampanye dengan \#hastag.

Hubungan kesadaran terhadap mass media advertising dan Twitter advertising terlihat pada akun resmi Menteri Komunikasi dan Informatika (Menkominfo) Republik Indonesia yang difollow 29.638 orang dalam dua bulan sejak konferensi pers di pesta blogger 2009. Untuk itu dapat disimpulkan semakin sering seseorang berinteraksi dengan iklan di media masa (mass media advertising) semakin tinggi keinginan individu mengadopsi Twitter advertising. Sehingga pada penelitian ini diajukan hipotesis :

H6 : Awareness akan mass media advertising mempengaruhi secara signifikan terhadap intention to adopt Twitter advertising.

\section{RANCANGAN PENELITIAN}

Berdasarkan pembagian Maholtra (2010), penelitian ini digolongkan ke dalam penelitian kuantitatif dan penelitian kualitatif. Populasi yang dituju adalah pengguna Twitter berusia 15 - 24 tahun di Jakarta, Bogor, Depok, Tanggerang dan Bekasi dengan metode sampling yang digunakan adalah non-probability sampling. Pengumpulan sampel dilakukan dengan metode judgmental sampling. Metode pengambilan sampel pada penelitian kualitatif ini menggunakan metode pengambilan sampel dengan variasi maksimum (Poerwandari, 2005).

Penentuan jumlah partisan berdasarkan jumlah sampel minimum dengan menggunakan rumus Sample size Determination for Proportions (Malhotra, 2010) Berdasarkan hal tersebut, peneliti berencana untuk mengambil 400 orang partisipan pengguna Twitter usia $15-24$ tahun di area Jabodetabek (Jakarta, Bogor, Depok, Tanggerang dan Bekasi) untuk berpartisipasi dalam penelitian ini. Untuk itu peneliti merencanakan mengambil 10 responden untuk mendapatkan pemahaman mendalam mengenai adopsi Twitter advertising.

Untuk mengumpulkan data empiris untuk meneliti hipotesis penelitian dan pertanyaan yang diperoleh dari theoretical framework, maka penelitian ini mengunakan instrumen penelitian dengan kuesioner. Bentuk kuesioner adalah pertanyaan tertutup (closed-ended). Responden akan diberikan skala interval dengan pengukuran 6-point scale sebagai pilihan atas jawaban yang diberikan. Penggunaan skala 1-6 digunakan untuk menghindari kecenderungan partisipan untuk memilih nilai tengah atau netral, yang biasa disebut effect of central tendency (Neuman, 1974). Data kualitatif dikumpulkan dengan wawancara mendalam 
yang dilakukan dengan tatap muka langsung.

Berdasarkan teori dan konsep technology acceptance dalam mengukur adopsi, peneliti memodifikasi item pengukuran adopsi untuk penelitian adopsi Twitter advertising berdasarkan Tsang, Ho and Liang, 2004, Boer, Westholf \& Yang, 2007 dan Giles dalam Soroa-Koury, 2008, Venkatesh \& Davis (2000), Moore \& Benbasat, 1991 dalam Tanakijal et al, 2010, Bamba \& Barnes, 2007 dan Okazaki, 2007. Peneliti memilih alat ukur tersebut dengan alasan menggambarkan determinan adopsi Twitter advertising, mencakup ranah kognitif dan afektif sesuai dengan teori dan model yang dipergunakan dalam penelitian ini.

Selanjutnya, alat ukur Twitter advertising tersebut diuji coba dengan melakukan pre-test kepada 30 orang yang memiliki karakter yang sama dengan responden nantinya. Dengan hasil pre-test, peneliti melakukan analisis item dengan melakukan uji validitas dan reabilitas dengan menggunakan SPSS 19. Berdasarkan hasil pre-test, peneliti meminta pertimbangan ahli expert judgement untuk menghilangkan atau mempertahankan item - item pada kuesioner. Dengan pertimbangan dari expert judgment peneliti melakukan pengurangan item sebanyak 2 item yang validitasnya lebih rendah dibandingkan dengan item-item lainnya. Selain itu, tim peneliti juga merevisi pertanyaan pada 3 item mengingat partisipan memiliki permasalahan dalam memahami pertanyaan tersebut. Kuesioner akhir terdiri dari 4 halaman, 6 pertanyaan demografis dan 46 pertanyaan menggunakan skala 1-6. Uji coba kuesioner ini dilakukan kembali guna memastikan keseluruhan kuesioner benar benar realibel dan valid kepada 30 orang yang memiliki karakteristik yang sama dengan responden nantinya. Pemilihan ke 30 orang ini berbeda dengan responden pre-test pertama.

\section{PEMBAHASAN}

Melalui pre-test untuk yang kedua kalinya, dinyatakan bahwa 46 item yang mewakili 6 (enam) variabel technology acceptance pada alat ukur adopsi Twitter advertising adalah valid, yaitu item - item yang memiliki koefisien korelasi dengan kelompok kriteria sebesar 0,361 atau lebih.Metode pengambilan keputusan pada uji validitas menggunakan batasan $r$ tabel sebesar 0,361 dengan $n=30$ (Azwar, 1999).

Pada uji reabilitas alat ukur adopsi Twitter advertising, diperoleh koefisien alpha sebesar 0,914. Oleh karena itu, dapat dikatakan bahwa alat ukur adopsi Twitter advertising cukup reliabel (Nunnaly \& Bernstein, 1994).

Pada saat pelaksanaan penelitian, diperoleh jumlah sampel berbeda dari tiap wilayah karena kesediaan responden untuk berpartisipasi berbeda di tiap - tiap wilayah. Peneliti menargetkan jumlah kuesioner yang disebar sebanyak 400. Dari 400 kuesioner yang disebar, 400 kuesioner yang kembali dan 330 kuesioner yang dapat diolah disebabkan karena terdapat beberapa kekurangan, seperti beberapa partisipan yang tidak sesuai dengan karakteristik yang ditentukan oleh peneliti dan beberapa partisipan yang tidak mengisi kuesioner secara lengkap. Pada tahap pelaksanaan peneliti mewawancara 5 orang dengan usia yang berbeda dan berdomisili di daerah yang berbeda karena telah terjadi saturation.

Dari data yang didapat, diketahui bahwa responden lebih banyak berjenis kelamin perempuan $(54 \%)$ daripada laki laki $(46 \%)$. Jika dilihat dari usia, responden lebih banyak memiliki berusia 18 tahun $(10,9 \%)$, kemudian 20 tahun $(10,7 \%)$ dan 19 tahun $(10,4 \%)$. Alat yang paling banyak 
digunakan untuk mengakses Twitter adalah Blackberry $(37,5 \%)$. Responden paling banyak membuat akun Twitter pada tahun 2010 (48,5\%), dengan aktivitas memfollow akun artis $(94,5 \%)$.

Hasil perhitungan mutiple regression pada tabel 4.3 menunjukkan bahwa keseluruhan dimensi yaitu attitude terhadap Twitter advertising, subjective norms terhadap Twitter advertising, perceived of usefulness, awareness tehadap mass media advertising, perceived behavioural control terhadap Twitter advertising, compatibility terhadap Twitter advertising berpengaruh (.158) secara signifikan $(\mathrm{p}<0.01)$ terhadap intention to adopt Twitter advertising. Dengan kata lain, terdapat $15,8 \%$ dari varians intention to adopt Twitter advertising yang dapat dijelaskan melalui keenam dimensi tersebut. Oleh karena itu, dimensi attitude terhadap Twitter advertising, subjective norms terhadap Twitter advertising, perceived of usefulness, awareness tehadap mass media advertising, perceived behavioural control terhadap Twitter advertising, compatibility terhadap Twitter advertising dapat dijadikan determinan dari intention to adopt Twitter advertising. Pengaruh masing - masing dimensi terhadap intention to adopt Twitter advertising dapat dilihat pada Tabel 1 .

Tabel 1.

Hasil Multiple Regression Masing - Masing Dimensi dengan Metode Stepwise

\begin{tabular}{|c||c|c|c|c|c||}
\hline \hline Model & $\begin{array}{c}\text { Unstandardized } \\
\boldsymbol{B}\end{array}$ & $\begin{array}{c}\text { Coeffocients } \\
\text { Std.Error }\end{array}$ & $\begin{array}{c}\text { Standardized } \\
\text { Coefficient } \\
\text { Beta }\end{array}$ & $\mathbf{t}$ & Sig. \\
\hline \hline $\begin{array}{c}1 \\
\text { Constan })\end{array}$ & 6.909 & .556 & & 12.434 & .000 \\
\hline \hline SN & .055 & .007 & .397 & 7.838 & .000 \\
\hline
\end{tabular}

Dependent Variable : Intention to adopt

Tabel 2.

Hasil Multiple Regression Masing - Masing Dimensi dengan Metode Stepwise

\begin{tabular}{|c||c||c||c||}
\hline Model & Beta In & t & Sig. \\
\hline \hline $\mathrm{At}$ & $.068^{*}$ & 1.258 & .209 \\
\hline \hline $\mathrm{PeU}$ & $-.078^{*}$ & -1.420 & .157 \\
\hline \hline $\mathrm{Co}$ & $.068^{*}$ & 1.318 & .188 \\
\hline \hline PBC & $.026^{*}$ & .514 & .608 \\
\hline \hline Compatibility & $-.056^{*}$ & -1.094 & .275 \\
\hline
\end{tabular}

*Predictors in the Model (Constant), SubNorms

Dependent Variable : Intention to adopt

Hasil perhitungan mutiple regression pada tabel 1 dan tabel 2 menunjukkan hanya subjective norms terhadap Twitter advertising yang berpengaruh terhadap intention to adopt Twitter advertising.
Subjective norms terhadap Twitter advertising berpengaruh (.055) secara signifikan $(\mathrm{p}<0.01)$ terhadap intention to adopt Twitter advertising. 


\section{DISKUSI}

Penelitian adopsi Twitter advertising ini membuktikan hubungan antara Twitter, mobile dan wireless tidak dapat dipisahkan. $72,5 \%$ reponden menyatakan mengakses Twitter melalui mobile yang memiliki wireless. Data yang mendukung hasil temuan tersebut adalah survei dari SalingSilang.com yang menyatakan $86,98 \%$ pengguna Twitter di Indonesia menggunakan aplikasi mobile untuk mengakses Twitter. Sehingga ketika meneliti mengenai adopsi Twitter advertising perlu diperhatikan mengenai adopsi mobile advertising dan adopsi mobile service karena Twitter merupakan aplikasi mobile.

Hasil analisis regresi mengkonfirmasi hipotesis 2 yaitu subjective norms terhadap Twitter advertising berpengaruh signifikan dan langsung terhadap intention to adopt Twitter advertising. Hipotesis 1, 3 , 4, 5, 6 yaitu attitude terhadap Twitter advertising, perceived usefulness terhadap Twitter advertising compatibility pada Twitter advertising, perceived behavioural control terhadap Twitter advertising, awareness akan mass media advertising berpengaruh signifikan dan langsung terhadap intention to adopt Twitter advertising tidak terkonfirmasi pada hasil analisis regresi.

Attitude terhadap Twitter advertising berpengaruh langsung dan signifikan terhadap intention to adopt Twitter advertising. Hasil tersebut tidak sejalan dengan penemuan dari penelitian terdahulu (Teo \& Pok, 2003; Lee, 2003; Khan\&Allil, 2010). Peneliti menduga perbedaan hasil penelitian yang terkait dengan variabel attitude towards behaviour pada penelitian ini dengan penelitian sebelumnya disebabkan adanya hubungan tidak langsung antara attitude terhadap Twitter advertising dengan intention to adopt. Hal ini merupakan masukan untuk riset berikutnya untuk meneliti variabel mediator atau moderator antara attitude terhadap Twitter advertising dan intention to adopt.

Subjective norms terhadap Twitter advertising adalah faktor yang pengaruhnya signifikan terhadap intention to adopt Twitter advertising. Disini subjective norms diartikan sebagai pengaruh sosial yang dapat menentukan behavior intention dari seseorang. Venkatesh\&Davis, 2000 membuktikan bahwa subjective norm mempengaruhi adopsi konsumen terhadap teknologi baru. Pada segmen muda usia 15 24 tahun, pengaruh sosial terutama teman sangatlah tinggi. Mereka sangat tergantung pada teman sebagai sumber referensi. Berdasarkan hasil kualitatif, segmen muda memperhatikan pandangan teman ketika hendak meretweet atau melakukan \#hastag Twitter advertising.

Hasil penelitian kualitatif adopsi mobile advertising pada segmen 15 sampai 24 tahun menunjukan bahwa keinginan untuk mengadopsi Twitter advertising pertama kali dipengaruhi oleh attitude terhadap Twitter advertising. Potential adopter telah terlebih dahulu memiliki sikap positif terhadap Twitter advertising. Sikap positif tersebut dapat terkait dengan produk atau jasa yang ditawarkan melalui Twitter advertising atau mengenai informasi produk atau jasa yang diberikan melalui Twitter advertising. Kemudian teman merupakan pengaruh lain yang membuat seseorang mengadopsi Twitter advertising. Teman merupakan referensi untuk mengetahui alaman akun resmi Twitter suatu perusahaan, pendorong mengadopsi Twitter advertising dan sebagai barometer diterima atau tidak diterimanya share informasi melalui Twitter advertising.

Perceived usefulness terhadap Twitter advertising tidak mempengaruhi intention to adopt Twitter advertising 
berdasarkan hasil multiple regresi dan hasil wawancara kualitatif. Pada Twitter advertising di segmen muda usia $15-24$ tahun intention to adopt tidak bergantung pada usefulness. Hal ini dibuktikan wawancara kualitatif, bahwa semakin banyak informasi yang di share dari akun resmi Twitter, kecenderungan yang dilakukan adalah mengunfollow akun resmi Twitter. Begitupula pada tindakan retweet dan \#hastag, seseorang tidak melakukan tindakan retweet dan \#hastag hanya karena informasi semata tetapi dari siapa informasi tersebut dilihat (melalui timeline). Hasil inilah yang merupakan ciri khas yang harus diperhatikan berkaitan dengan Twitter advertising.

Tidak signifikannya pengaruh dari compatibility pada Twitter advertising terhadap intention to adopt Twitter advertising menjelaskan bahwa seseorang memfollow akun resmi Twitter bukan karena compatibility dengan gaya searching di internet. Searching informasi produk atau jasa menjadi lebih mudah dengan adanya link yang diberikan pada Twitter advertising tetapi hal tersebut tidak mempengaruhi seseorang mengadopsi Twitter advertising. Variabel lain yang dinyatakan tidak signifikan mempengaruhi intention to adopt Twitter advertising adalah perceived behavioural control terhadap Twitter advertising dan awareness of mass media advertising. Hasil ini sejalan dengan Khan\&Alil, 2010 yang menyatakan bahwa perceived behavioural control dan awareness of mass media tidak berpengaruh terhadap intention to adopt mobile advertising di Syiria.

\section{KESIMPULAN}

Pada penelitian ini dibuktikan kombinasi teori dan model TRA, TPB, TAM dan DOI dapat mengukur adopsi Twitter advertising. Hal ini dibuktikan dengan hasil analisis regresi variabel - variabel yang berasal dari teori tersebut yaitu, attitude terhadap Twitter advertising, subjective norm pada Twitter advertising, perceived of usefulness dari Twitter advertising, compatibility pada Twitter advertising, perceived of behavioural control pada Twitter advertising dan awareness akan mass media advertising secara bersama mempengaruhi intention to adopt Twitter advertising. Terkait dengan penelitian sosial media advertising, penggabungan teori tersebut merupakan pembuktian bahwa kombinasi teori dan model TRA, TPB, TAM dan DOI dapat dipergunakan untuk mengukur adopsi pada sosial media advertising karena saat ini peneliti sebagian besar menggunakan satu teori.

\section{SARAN}

1. Pada penelitian ini, peneliti hanya mengambil sample segmen muda usia 15 - 24 tahun. Sebaiknya pada penelitian selanjutnya, diperluas sampel pada segmen usia yang lain agar didapatkan suatu gambaran yang menyeluruh mengenai adopsi Twitter advertising.

2. Dilakukan pengujian masing - masing teori dan model TRA, TPB, TAM dan DOI dalam bentuk penelitian eksperimen agar terlihat teori dan model manakah yang secara definitif paling dapat menjelaskan adopsi Twitter advertising.

3. Untuk penelitian selanjutnya, perlu dikhususkan mengenai adopsi Twitter advertising melalui mobile guna lebih menggali dan menjelaskan lebih spesifik strategi marketing yang tepat bagi mobile. 


\section{DAFTAR PUSTAKA}

Ahmad, I. (2010, Mei 15). Demi kulakan gosip, aku bikin akun di twitter. http://webcache.googleusercontent.com/search?q=cache:F3KzPCwrCTgJ:iraddin.wordpress.com/2 010/05/15/+tau+akun+di+TV+langsung+follow\&cd=1\&hl=id\&ct=clnk\&source=www.google.com diakses 24 Maret 2011.

Ajzen, I. (1991). Theory of planned behavior. Organizational Behavior and Human Decision Processes, 50, $179-211$

Azwar, S. (1999). Metode penelitian kualitatif. Jakarta: PT Gramedia Pustaka. Utama.

Bamba, F., \& Barnes, S. J. (2007). SMS advertising, permission and the consumer: a study. Business Process Management Journal, 13(6), 815-829.

Bilgihan, A., Nusair, K., \& Okumus, F., (2009), Social networking websites: do generation Y use them before making decisions for hotels and restaurants? http://scholarworks.umass.edu/cgi/viewcontent.cgi?article=1275\&context=gradconf_hospitality diakses 15 Januari 2011.

Calisir, F. (2003). Web advertising vs other media : young consumer's view. Internet Research. Electronic Networking Application and Policy, 13 (5), 356-363.

Chen, L. (2009). Online consumer behavior: an empirical study based on theory of planned behavior. Diss. of U Nebraska, UMI, 3355613.

Cheng, L \& Evans, M (2009). An In-Depth Look Inside the Twitter World. http://www.sysomos.com/insidetwitter/ diakses 20 Januari 2011.

Chou, A. Y., \& Chou, D. C., (2009). Information system characteristics and social network software adoption. http://www.swdsi.org/swdsi2009/Papers/9K02.pdf diakses 15 Januari 2011.

Davis, F. D. (1989). Perceived usefulness, perceived ease of use, and user acceptance of information technology. MIS Quarterly, 13 (3), 319-339.

Doherty, B. (2010, November 22). Why Indonesians are all a-Twitter. http://www.guardian.co.uk/technology/2010/nov/22/indonesians-worlds-biggest-users-of-twitter diakses 28 Desember 2010.

Exploring the Use of Twitter Around the World oleh Sysomoc diakses 23 Maret 2011.

Faisal, M. (2011). Wawancara oleh penulis, 15 Januari 2011.

Fishbein, M., \& Ajzen, I. (1975). Belief, attitude, intention, behavior: an introduction to theory and research. Addison- Wesley, reading, MA.

Glaser, M. (2007). Twitter founders thrive on micro-blogging constraints. http://www.pbs.org/mediashift/2007/05/your-guide-to-micro-blogging-and-twitter135.html diakses 21 Januari 2011.

Godin, S. (1999). Permission marketing: turning strangers into friends, and friends into customers. New York: Simon \& Schuster, Inc.

Grainger, J., (2010). Social media and the fortune 500: how the fortune 500 uses, percieves and measures social media as a marketing tool. Ths. U of North Carolina. UMI, 1476672.

Guilford, J. P. \& Fruchter, B. (1978). Fundamental statistics in psychology and education.Tokyo: McGraw Hill Kogakusha.

Hawkins \& Mothersbaugh. (2010). Consumer behavior: building marketing strategy, (11 ${ }^{\text {th }}$ Ed.). New York: McGraw-Hill.

Hidayat, T., (2011, Maret 31 - April 13). Ini dia, social media marketing. SWA Sembada, pp. 94 - 97.

Jun, J.W. \& Lee, S. (2007). Mobile media use and its impact on consumer attitudes toward mobile advertising. International Journal of Mobile Marketing, 2 (1), pp. 50-59.

Kementerian Pemuda dan Olahraga. (2009). Penyajian data dan informasi kementerian pemuda dan olahraga.

http://www.kemenpora.go.id/pdf/PENYAJIAN\%20DATA\%20INFORMASI\%20KEMENTERIAN \%20PEMUDA\%20DAN\%20OLAHRAGA\%20TAHUN\%202009.pdf diakses 20 Januari 2011. 
Kim, S. (2008). Appropriation of wireless technology: direct impacting factors on the youth's adoption intention and usage of the wireless aplication protocol phone, Information Technology Journal, 1 9.

Khan, M.N., Allil, K. (2010). Determinants of mobile advertising adoption: a cross-country comparison of India and Syria, IJMM Summer, 5 (1), 41-59.

Koutalakis, S. (2009, September 1). New Mzinga survey reveals 86 percent of organizational use social technologies for business purposes. http://www.mzinga.com/company/newsdetail.asp?lang=en\&newsID=252\&strSection=company\&st rPage=news diakses 15 Januari 2011.

Lee, J. (2008). Predicting the usage of online video advertising: using the theory of planned behavior. Diss. U of Michigan. UMI, 1459222.

Lee, S. G. (2003). An integrative study of mobile technology adoption based on the technology acceptance model, theory of planned behavior and diffusion of innovation theory. Diss. U of Nebraska. UMI, 3104619.

Lexhagen, M., Nysveen, H., \& Hem, L. E. (2005). Festival coordination: an exploratory study on intention to use mobile devices for coordination of a festival. Event Managemnet, 9, 133- 146.

Liu, I. L. B., Cheung, C. M. K., \& Lee, M. K. O. (2010). Understanding twitter usage: what drive people continue to tweet. PACIS 2010 Proceedings. Paper 92.

Malhotra, N. (2010). Marketing research: an applied orientation (6 ${ }^{\text {th }}$ Ed.). New Jersey: Prentice Hall International, Inc.

Menjawab rakyat dengan nge-tweet. (2010, Januari 18). http://mix.co.id/index.php?option=com_content\&task=view\&id=540\&Itemid=58 diakses 23 Maret 2011.

Mischaud, E., (2007), Twitter: Expressions of the Whole Self An investigation into user appropriation of a web-based communications platform. http://www2.1se.ac.uk/media@1se/research/mediaWorkingPapers/MScDissertationSeries/Mishaud_ Final.pdf diakses 20 Januari 2011.

Nunnally, J. \& Bernstein, I. (1994). Psychometric theory. New York: McGraw-Hill, Inc.

Okazaki, S. (2007). Lesson learned from i-mode: what makes consumers click wireless banner ads? Computers in Human Behaviour, 23, 1692-1719.

Patton, M.Q. (1990). Qualitative evaluation and research methods. Newbury Park: Sage Publications.

Perceptions of Libraries and Information Resources (2005). Perceptions of potential college student. http://www.oclc.org/reports/pdfs/studentperceptions_part5.pdf diakses 25 Mei 2011.

Pertiwi, M. (2010, Oktober). Integrasikan situs web dengan media sosial. Digital Marketing, pp. 38-39.

Poerwandari, E.K. (2005). Pendekatan kualitatif untuk penelitian perilaku manusia. Jakarta: Lembaga Pengembangan Sarana Pengukuran dan Pendidikan Psikologi Fakultus Psikologi Universitas Indonesia.

Radwanick, S. (2010, Agustus 11). Indonesia, Brazil and Venezuela Lead Global Surge in Twitter Usage. http://www.comscore.com/Press_Events/Press_Releases/2010/8/Indonesia_Brazil_and_Venezuela_ Lead_Global_Surge_in_Twitter_Usage diakses 11 Januari 2011.

Rogers, E. M. (2003). Diffusion of innovation (5th ed.). New York: Simon \& Schuster, Inc.

Sanghyun, K., (2008). Appropriation of wireless technology: direct impacting factors on youth's adoption intention and usage of the wireless application protocol phone. Inform Technol. J., 1-9.

Sendecka, L. (2006). Adoption of mobile services : moderating effects of service's information intensity. Ths of Norges Handelshøyskole.

Soroa-Koury, S., (2008). Consumers' responses to mobile advertising a normative social behaviour perspective. Ths of U. Texas at El Paso. UMI, 1453834.

Slim, T. (2011). Tropicana Slim Homepage. http://www.tropicanaslim.com/tentang-tropicana-slim diakses 23 Maret 2011. 
Stratmann, J. (2010, Agustus 16). 5 reasons why people follow brands on Twitter. http://www.freshnetworks.com/blog/2010/08/5-reasons-people-follow-brands-twitter/ diakses 27 Maret 2011.

Suwarna, B., \& Febriane, S., (2010, Desember 26). Rendang pun “berselancar” di internet. Kompas, pp. 32.

Tanakinjal,G. H., Deans, K. R., \& Gray, B. J., (2010). Third screen communication and the adoption of mobile marketing: a malaysia perspective. International Journal of Marketing Studies, 2 (1), 36-47.

Tapscott, D. (2009). Grown up digital: how the net generation is changing your world. New York: McGrawHill.

Taylor, S. \& Todd, P. (1995). Understanding information technology usage: a test of computing models. Information Systems Research, 6 (2), 144-176.

Teo, T., \& Pok, S. (2003). Adoption of WAP-enabled mobile phones among Internet users. Omega, 31 (6), 483-498.

Venkatesh, V., \& Davis, F. D. (2000). A theoretical extension of the technology acceptance model: four longitudinal field studies. Management Science, 45(2), 186-204.

Venkatesh, V., Michael G. Morris, M. G., Davis, G. B., \& Davis, F. D. (2003). User acceptance of information technology: toward a unified view. MIS Quarterly, 27 (3), 425-478.

Widyaharsana, J. I. (2010). Mobile marketing sebagai media pemasaran. Jakarta: PPM Manajemen. 